\title{
UMA HISTÓRIA DE AMOR, CONQUISTA E VINGANÇA: UMA ANÁLISE SEMIÓTICA DO VIDEOCLIPE BAD ROMANCE UNA HISTORIA DE AMOR, DE CONQUISTA Y DE LA VENGANZA: UN ANÁLISIS SEMIÓTICO DEL VIDEOCLIP BAD ROMANCE
}

\author{
Profa. Dra. Patricia M. F Coelho \\ Universidade Santo Amaro (UNISA/BRASIL) \\ Centro Universitário Internacional - UNINTER/BRASIL \\ patriciafariascoelho@gmail.com
}

\begin{abstract}
Resumo: A cada dia os videoclipes, filmes de curta duração, ganham mais espaço na vida das pessoas, que não precisam mais ficar diante de uma televisão para assistir a esse tipo de produção artística. Atualmente, é bastante acessar determinados sites da internet e selecionar com facilidade seus clipes preferidos, podendo vê-los ao longo do dia. Para este estudo, selecionamos como corpus o videoclipe da canção Bad Romance, interpretada pela cantora americana Lady Gaga, lançada em 2010 como primeira canção do álbum The Fame Monster. A escolha desse videoclipe se deu pelo fato de ele trazer uma contradição entre sua linguagem visual e sua linguagem oral/verbal (a letra da música). Temos dois objetivos, a saber: (i) analisar os níveis narrativo, discursivo (temas e figuras) e fundamental no videoclipe; (ii) averiguar seus aspectos sincréticos a partir das categorias cromáticas, eidéticas e topológicas. Como arcabouço teórico nos ancoramos nos estudos sobre sincretismo, propostos por J. M. Floch (1985, 1987, 1990 e 2001), Oliveira e Teixeira (2009), sobre as categorias eidéticas, topológicas e cromáticas, em Coelho (2011), os estudos de Greimas e Courtés (1996 e 2008), Barros (2001 e 2002) e Fiorin (2009), sobre os níveis narrativo e discursivo do plano do conteúdo. A metodologia utilizada nesta pesquisa foi a descritiva. Os resultados mostram que a aplicação da semiótica francesa em um corpus midiático é profícua e contribui para os semioticistas reiterarem a relevância do modelo semiótico proposto por Greimas.
\end{abstract}

Palavras-chaves: Semiótica Discursiva. Videoclipe. Sincretismo.

Resumen: Cada día más los videoclips, cortometrajes, ganan más espacio en la vida de las personas, que ahora ya no necesitan estar en frente de la televisión para verlos. Hoy en día si una persona se conecta a Internet puede seleccionar fácilmente sus clips favoritos y se puede oír y ver a lo largo del día. Este medio difunde y propaga la música de varios artistas. Entre los muchos videoclip, seleccionamos como corpus, para este estudio, el videoclipe de la canción Bad Romance de la cantante estadounidense Lady Gaga, lanzado en 2010, con la primera canción en el álbum The Fame Monster. La elección de este videoclip se debe al hecho de el traer una contradicción entre el lenguaje visual y el lenguaje oral / verbal (la letra de la música) - lo que justifica nuestra elección. Tenemos dos objetivos, a saber: (i) analizar el nivel narrativo y el nivel discursivo (temas y figuras) en el videoclip; y (ii) determinar los aspectos sincréticos del videoclip Bad Romance, de las categorías cromáticas, eidéticos y topológicas. Como marco teórico apoyamonos en los estudios de sincretismo propuesto por J. M. Floch (1985; 1987; 1990; 2001), Oliveira y Teixeira (2009) y Coelho (2011) en las categorías eidéticos, topológicas y cromáticas y estudios de Greimas y Courtés (1996; 2008), Barros (2001; 2002) y Fiorin (2009) sobre la narrativa y el nivel discursivo del plan de contenido. La metodología utilizada en esta investigación es descriptiva. Los resultados muestran que la aplicación de la semiótica francesa en un corpus de los medios de comunicación es rentable y contribuye a los semioticistas reconfirmen la importancia del modelo semiótico propuesto por Greimas.

Palabras clave: Semiótica Discursiva. Videoclip. Sincretismo.

\section{Introduçãa}

Este trabalho pretendeu analisar o videoclipe da canção Bad Romance, interpretada pela cantora americana Lady Gaga, lançada em 2010 como primeira canção do álbum The Fame Monster. O corpus deste estudo foi selecionado pelo fato de o videoclipe apresentar uma contradição entre a linguagem visual e a linguagem oral/verbal (a letra da música), pois em alguns momentos observamos uma relação harmoniosa entre imagem e verbal (junção eufórica), 
e em outros momentos há uma contradição entre letra e visual (disjunção disfórica) - o que justifica e explica essa nossa escolha.

Compreende-se por videoclipe um filme de curta duração, produzido em suporte eletrônico, que tanto pode se apresentar em formato analógico quanto digital. Essa mídia tem o objetivo de divulgar músicas, filmes e outras produções artísticas. Desse modo, pode ser considerada uma metamídia, isto é, ela traz, em sua própria textualidade, uma outra mídia.

O arcabouço teórico que sustenta este trabalho reúne as pesquisas sobre sincretismo propostas por J. M. Floch (1985, 1987, 1990 e 2001), Oliveira e Teixeira (2009), Coelho (2011), sobre as categorias eidéticas, topológicas e cromáticas, e os estudos de Greimas e Courtés (1996 e 2008), Barros (2001 e 2002) e Fiorin (2009), sobre o nível narrativo, discursivo e fundamental do plano do conteúdo.

Temos como objetivos analisar os níveis narrativo, discursivo (temas e figuras) e fundamental no videoclipe e verificar os aspectos sincréticos encontrados no videoclipe $\mathrm{Bad}$ Romance, a partir do estudo das categorias cromáticas, eidéticas e topológicas.

A metodologia utilizada nesta pesquisa será a descritiva, como sugere a tradição semiótica. Dividimos este estudo nos seguintes tópicos: 1. Um breve panorama da semiótica francesa: plano do conteúdo e sincretismo; 2 . Análise do videoclipe a partir dos níveis narrativo, discursivo e fundamental; 3. Análise do videoclipe: níveis narrativo e discursivo; 4. As categorias cromática, topológica e eidética: um estudo das cenas do videoclipe e 5. Considerações finais.

Os resultados mostram que a aplicação da semiótica discursiva em corpus de natureza midiática auxilia os semioticistas a reiterarem a pertinência do modelo semiótico proposto por Greimas.

\section{Um breve panorama da semiótica francesa: plano do conteúdo e sincretismo}

A semiótica discursiva é conhecida como a teoria da significação, uma vez que nos permite compreender "o que o texto diz e como ele faz para dizer o que diz" (BARROS, 2002, p. 11). Para os semioticistas, o sentido que se apreende nos textos nunca aparece ou é entendido como algo pronto e acabado, mas como algo que se atinge por um parecer do sentido, uma vez que o estudioso nunca terá, de fato, acesso ao seu verdadeiro significado.

Ainda, Barros (2002: p.13) explica que a semiótica examina o plano do conteúdo por meio do percurso gerativo de sentido, que vai do mais simples e abstrato ao mais complexo e concreto, dividindo-se "em três níveis, a saber: narrativo, discursivo e fundamental" (BEIVIDAS, 2006, p. 48). De acordo com Coelho (2011), no nível fundamental, ocorre a oposição mínima de sentido pelo qual o discurso se constrói; no nível narrativo, há uma sucessão de transformações 
de estados operadas por um sujeito em busca do seu objeto de valor, e as relações contratuais que se estabelecem entre esses sujeitos e o nível discursivo é o que se apresenta mais próximo da manifestação textual, estudando as relações entre enunciação e enunciado e entre enunciador e enunciatário, bem como tematização e figurativização dos valores narrativos.

Como nos explica Fiorin (2009, p. 35), o sincretismo se define, "como um todo de significação e, portanto, há um único conteúdo manifestado por diferentes substâncias da expressão". Floch (1985, p. 141-144), um dos principais estudiosos do sincretismo, explica-o como resultado da relação entre o plano do conteúdo e o plano da expressão e, por isso, deve ser compreendido como um único sistema semiótico. A partir de suas pesquisas, esse investigador desenvolveu um modelo de análise para o texto sincrético, propondo a existência das seguintes categorias do plano da expressão: eidéticas (forma), cromáticas (cor) e topológicas (organização espacial) - as quais seriam análogas às categorias do plano do conteúdo.

Em nosso corpus, o videoclipe, temos um objeto sincrético, visto que apresenta mais de dois tipos de linguagens: , a sonora, a visual e a verbal, não sendo apenas uma soma deles. De acordo com Oliveira (2009), a união dessas linguagens gera outras correlações intersistêmicas que passam a ter papel fundamental na compreensão do objeto em análise e, por isso, não podem ser desprezadas, uma vez que não há apagamento de uma das linguagens para beneficiar a outra e nem uma fusão simples entre elas. Discini (2009, p. 2005), complementando as afirmações de Oliveira (2009: p 238), explica que o sincretismo se estabelece de duas formas:

\begin{abstract}
A primeira é a estratégia contratual, na qual verbal e visual se ligam a uma única isotopia ${ }^{1}$. O segundo tipo é a estratégia polêmica que pode ocorrer, por sua vez, de duas maneiras. Na primeira delas, verbal e visual inauguram uma segunda isotopia por complementaridade ou contraditoriedade. A outra forma de estratégia polêmica é aquela em que verbal e visual se negam mutuamente.
\end{abstract}

Em nosso videoclipe, temos a segunda forma de sincretismo, a estratégia polêmica, uma vez que verbo e visual se negam entre si. Dessa forma, nosso corpus é um objeto midiático que se utiliza do sincretismo por contrariedade, construído assim intencionalmente pelo enunciador como estratégia, utilizando a capacidade dessa mídia para produzir vários efeitos de sinestesias a fim de manipular o enunciatário. Floch (Apud Greimas; Courtés, 1986, p. 218) afirma que

o recurso a uma pluralidade de linguagens de manifestação, para construir um texto sincrético, decorre, no nosso entender, de uma estratégia global de comunicação sincrética que "suscita", por assim dizer, o contínuo discursivo resultante da textualização, portando por "investir" a linearidade do texto em substâncias diferentes; em certos casos, os procedimentos de sincretização podem resultar de verdadeiras sinestesias.

\footnotetext{
${ }^{1}$ De acordo com Bertrand (2003, p. 153) isotopia é a "permanência de um efeito de sentido ao longo da cadeia do discurso".
} 
Esses recursos utilizados pelo enunciatário na criação do enunciado - videoclipe - estão ligados à relação que se estabelece entre as linguagens, que dizem e se mostram, de forma explícita ou implícita, em seu conteúdo. Sendo assim, o videoclipe em questão é um elemento que merece o nosso olhar, uma vez que, a partir das ferramentas oferecidas pela semiótica francesa, analisamos os níveis fundamental, narrativo e discursivo, observando as relações sincréticas que ali se instauram.

\section{Análise do videoclipe: níveis narrativo, discursivo e fundamental.}

Serão apresentadas, a seguir, a letra da musica em português e em inglês.

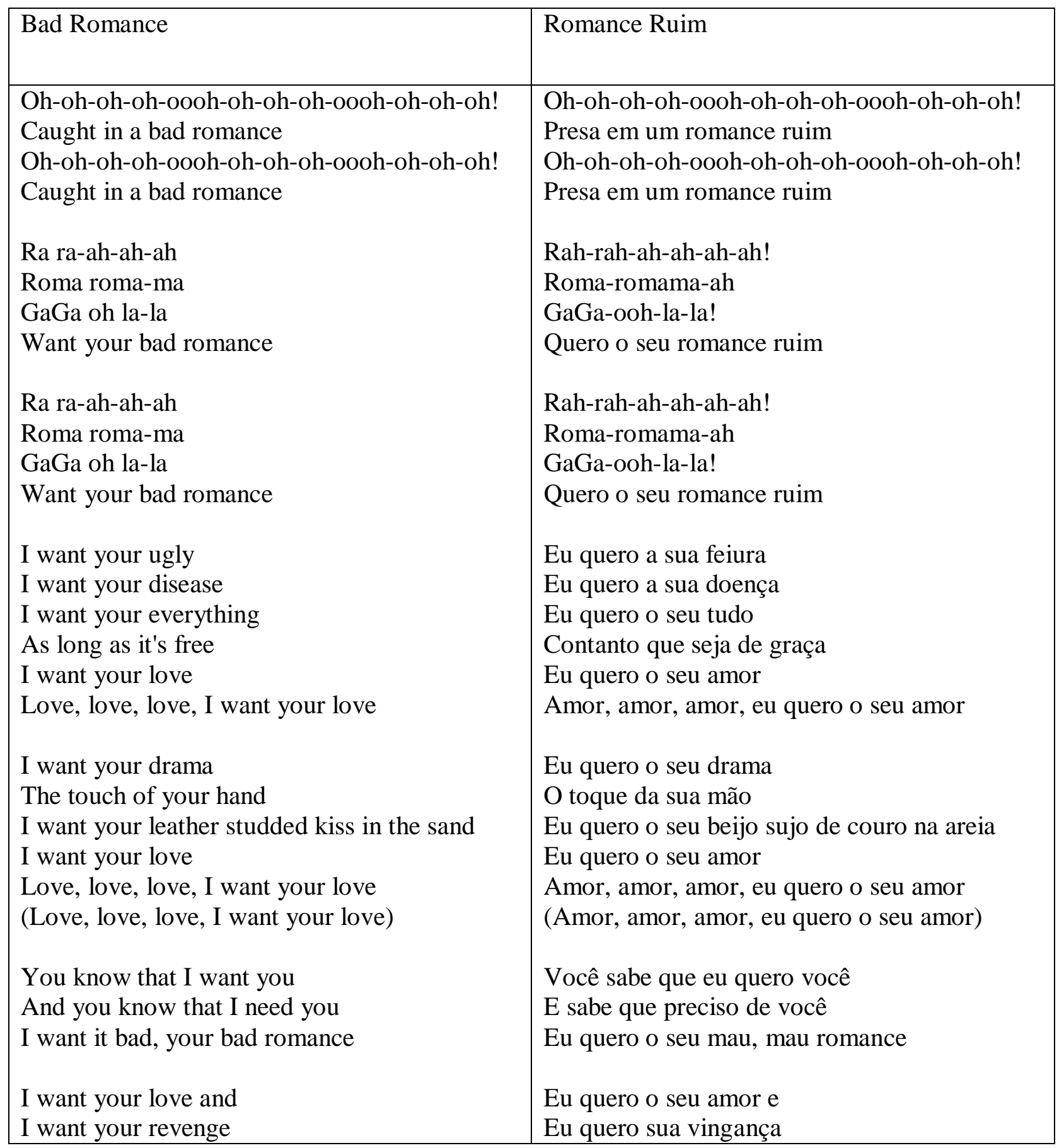




\begin{tabular}{|c|c|}
\hline $\begin{array}{l}\text { You and me could write a bad romance } \\
\text { (Oh-oh-oh--oh-oooh!) } \\
\text { I want your love and } \\
\text { All your lover's revenge } \\
\text { You and me could write a bad romance }\end{array}$ & $\begin{array}{l}\text { Você e eu poderíamos escrever um romance } \\
\text { ruim } \\
\text { (Oh-oh-oh-oh-oooh!) } \\
\text { Eu quero o seu amor } \\
\text { E a vingança de todas as suas amantes } \\
\text { Você e eu poderíamos escrever um romance } \\
\text { ruim }\end{array}$ \\
\hline $\begin{array}{l}\text { Oh-oh-oh-oh-oooh-oh-oh-oh-oooh-oh-oh-oh! } \\
\text { Caught in a bad romance } \\
\text { Oh-oh-oh-oh-oooh-oh-oh-oh-oooh-oh-oh-oh! } \\
\text { Caught in a bad romance }\end{array}$ & $\begin{array}{l}\text { Oh-oh-oh-oh-oooh-oh-oh-oh-oooh-oh-oh-oh! } \\
\text { Presa a um romance ruim } \\
\text { Oh-oh-oh-oh-oooh-oh-oh-oh-oooh-oh-oh-oh! } \\
\text { Presa em um romance ruim }\end{array}$ \\
\hline $\begin{array}{l}\text { Ra ra-ah-ah-ah } \\
\text { Roma roma-ma } \\
\text { GaGa oh la-la } \\
\text { Want your bad romance }\end{array}$ & $\begin{array}{l}\text { Rah-rah-ah-ah-ah-ah! } \\
\text { Roma-roaama-ah } \\
\text { GaGa-ooh-la-la! } \\
\text { Quero o seu romance ruim }\end{array}$ \\
\hline $\begin{array}{l}\text { I want your horror } \\
\text { I want your design } \\
\text { 'Cuz you're a criminal } \\
\text { As long as your mine } \\
\text { I want your love } \\
\text { (Love, love, love, I want your love) }\end{array}$ & $\begin{array}{l}\text { Eu quero o seu horror } \\
\text { Eu quero o seu estilo } \\
\text { Porque você é um criminoso } \\
\text { Contanto que seja meu } \\
\text { Eu quero o seu amor } \\
\text { (Amor, amor, amor, eu quero o seu amor) }\end{array}$ \\
\hline $\begin{array}{l}\text { I want your psycho } \\
\text { Your vertigo stick } \\
\text { Want you in my rear window } \\
\text { Baby, you're sick } \\
\text { I want your love } \\
\text { Love, love, love } \\
\text { I want your love } \\
\text { (Love, love, love, I want your love) }\end{array}$ & $\begin{array}{l}\text { Eu quero a sua obsessão } \\
\text { Sua vara vertical } \\
\text { Quero você na minha janela traseira } \\
\text { Querido, você é doente } \\
\text { Eu quero o seu amor } \\
\text { Amor, amor, amor } \\
\text { Eu quero o seu amor } \\
\text { (Amor, amor, amor, eu quero o seu amor) }\end{array}$ \\
\hline $\begin{array}{l}\text { You know that I want you } \\
\text { ('Cuz I'm a free bitch baby) } \\
\text { And you know that I need you } \\
\text { I want a bad, bad romance }\end{array}$ & $\begin{array}{l}\text { Você sabe que eu quero você } \\
\text { (Porque eu sou uma vadia livre, baby!) } \\
\text { E você sabe que eu preciso de você } \\
\text { Eu quero o seu mau,mau romance }\end{array}$ \\
\hline $\begin{array}{l}\text { I want your love and } \\
\text { I want your revenge } \\
\text { You and me could write a bad romance } \\
\text { (Oh-oh-oh-oh-oooh!) } \\
\text { I want your love and } \\
\text { All your lover's revenge } \\
\text { You and me could write a bad romance }\end{array}$ & $\begin{array}{l}\text { Eu quero o seu amor e } \\
\text { Eu quero sua vingança } \\
\text { Nós poderíamos escrever um romance ruim } \\
\text { (Oh-oh-oh--oh-oooh!) } \\
\text { Eu quero o seu amor e } \\
\text { E a vingança de todas as suas amantes } \\
\text { Você e eu poderíamos escrever um romance } \\
\text { ruim }\end{array}$ \\
\hline $\begin{array}{l}\text { Oh-oh-oh-oh-oooh-oh-oh-oh-oooh-oh-oh-oh! } \\
\text { Caught in a bad romance }\end{array}$ & $\begin{array}{l}\text { Oh-oh-oh-oh-oooh-oh-oh-oh-oooh-oh-oh-oh! } \\
\text { Presa em um romance ruim }\end{array}$ \\
\hline
\end{tabular}




\begin{tabular}{|c|c|}
\hline $\begin{array}{l}\text { Oh-oh-oh-oh-oooh-oh-oh-oh-oooh-oh-oh-oh! } \\
\text { Caught in a bad romance }\end{array}$ & $\begin{array}{l}\text { Oh-oh-oh-oh-oooh-oh-oh-oh-oooh-oh-oh-oh! } \\
\text { Presa em um romance ruim }\end{array}$ \\
\hline Ra ra-ah-ah-ah & Rah-rah-ah-ah-ah-ah! \\
\hline Roma roma-ma & Roma-romama-ah \\
\hline GaGa oh la-la & GaGa-ooh-la-la! \\
\hline Want your bad romance & Quero o seu romance ruim \\
\hline Ra ra-ah-ah-ah & Rah-rah-ah-ah-ah-ah! \\
\hline Roma roma-ma & Roma-romama-ah \\
\hline GaGa oh la-la & GaGa-ooh-la-la! \\
\hline Want your bad romance & Quero o seu romance ruim \\
\hline Walk, walk fashion, baby & Ande, ande na moda, baby \\
\hline Work it! & Vamos! \\
\hline Move that bitch c-razy & Deixe a vadia louca \\
\hline Walk, walk fashion, baby & Ande, ande na moda, baby \\
\hline Work it! & Vamos! \\
\hline Move that bitch c-razy & Deixe a vadia louca \\
\hline Walk, walk fashion, baby & Ande, ande na moda,baby \\
\hline Work it! & Vamos! \\
\hline Move that bitch c-razy & Deixe a vadia louca \\
\hline Walk, walk passion, baby & Ande, ande com paixão, baby \\
\hline Work it! & Vamos! \\
\hline I'm a free bitch, baby & Eu sou uma vadia livre, baby \\
\hline I want your love & Eu quero seu amor \\
\hline And I want your revenge & E eu quero a sua vingança \\
\hline I want your love & Eu quero o seu amor \\
\hline I don't wanna be friends & Eu não quero que sejamos amigos \\
\hline Je veux ton amour & Eu quero seu amor \\
\hline Et je veux ta revanche & E eu quero a sua vingança \\
\hline Je veux ton amour & Eu quero o seu amor \\
\hline I don't wanna be friends & Eu não quero que sejamos amigos \\
\hline Oh-oh-oh-oh-oooh! & (Oh-oh-oh-oh-oooh!) \\
\hline I don't wanna be friends & Eu não quero que sejamos amigos \\
\hline (Caught in a bad romance) & (Presa em um romance ruim) \\
\hline I don't wanna be friends & Eu não quero que sejamos amigos \\
\hline Oh-oh-oh-oh-oooh! & (Oh-oh-oh-oh-oooh!) \\
\hline Want your bad romance & Quero o seu romance ruim \\
\hline (Caught in a bad romance) & (Presa em um romance ruim) \\
\hline Want your bad romance! & Quero o seu romance ruim! \\
\hline I want your love and & Eu quero o seu amor \\
\hline I want your revenge & Eu quero sua vingança \\
\hline You and me could write a bad romance & Você e eu poderíamos escrever um romance \\
\hline
\end{tabular}




\begin{tabular}{|c|c|}
\hline $\begin{array}{l}\text { Oh-oh-oh-oh-oooh! } \\
\text { I want your love and } \\
\text { All your lovers' revenge } \\
\text { You and me could write a bad romance } \\
\text { Oh-oh-oh-oh-oooh-oh-oh-oh-oooh-oh-oh-oh! } \\
\text { Want your bad romance } \\
\text { (Caught in a bad romance) } \\
\text { Want your bad romance } \\
\text { Oh-oh-oh-oh-oooh-oh-oh-oh-oooh-oh-oh-oh! } \\
\text { Want your bad romance } \\
\text { (Caught in a bad romance) } \\
\text { Ra ra-ah-ah-ah } \\
\text { Roma roma-ma } \\
\text { GaGa oh la-la } \\
\text { Want your bad romance }\end{array}$ & $\begin{array}{l}\text { ruim } \\
\text { (Oh-oh-oh--oh-oooh!) } \\
\text { Eu quero o seu amor } \\
\text { E a vingança de todas as suas amantes } \\
\text { Você e eu poderíamos escrever um romance } \\
\text { ruim } \\
\text { Oh-oh-oh-oh-oooh-oh-oh-oh-oooh-oh-oh-oh! } \\
\text { Quero o seu romance ruim } \\
\text { (Presa em um romance ruim) } \\
\text { Quero o seu romance ruim } \\
\text { Oh-oh-oh-oh-oooh-oh-oh-oh-oooh-oh-oh-oh! } \\
\text { Quero o seu romance ruim } \\
\text { (Presa em um romance ruim) } \\
\text { Ra ra-ah-ah-ah } \\
\text { Roma roma-ma } \\
\text { GaGa oh la-la } \\
\text { Quero o seu romance ruim }\end{array}$ \\
\hline
\end{tabular}

Tradução disponível em: https://www.letras.mus.br/lady-gaga/1561430/traducao.html. Acesso: 24 dez. 2016.

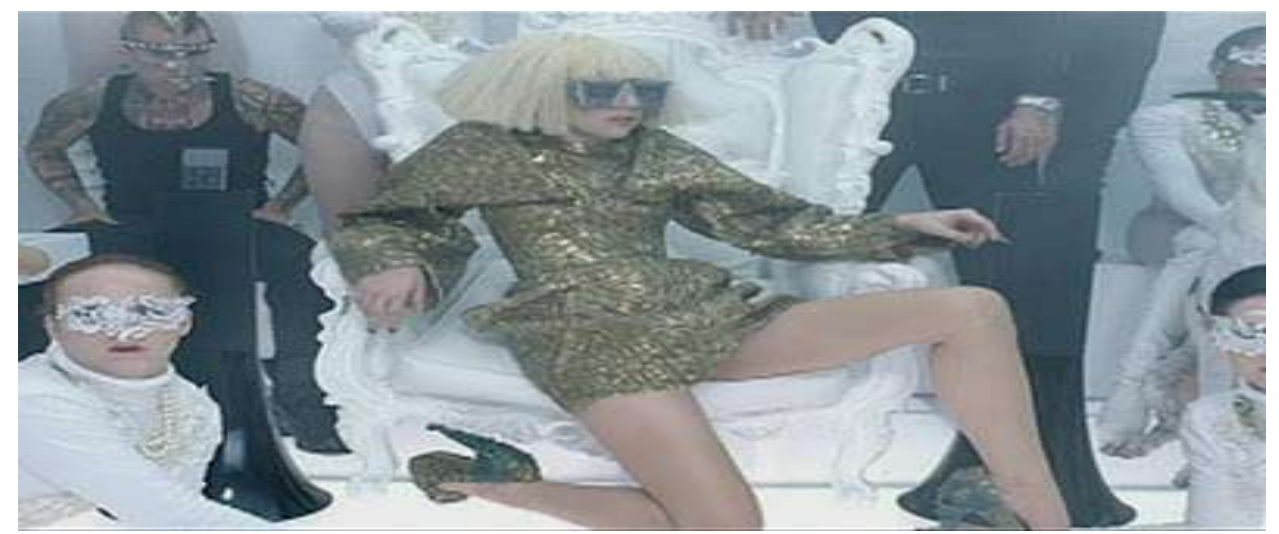

FIGURA 1 - Disponível em: https://www.youtube.com/watch?v=qrO4YZeyl0I Acesso em: 14 dez. 2016.

\subsection{Nível narrativo}

A semiótica francesa compreende o programa narrativo como um enunciado de fazer que rege um enunciado de estado. $\mathrm{Na}$ abertura do videoclipe, temos uma imagem que mostra o início de um jogo, ou seja, o sujeito semiótico 1 (S1), representado por Lady Gaga, que aperta um botão. É esse momento inicial da narrativa sincrética, pois quando ela, decide apertar o botão, Lady Gaga se desfribila em vários papéis actanciais, como explica Tatit (2010) em sua obra Semiótica à luz de Guimarães Rosa. Dessa forma, segundo o pesquisador (2010) um ator pode concentrar nele todos os papéis actanciais de um texto - como ocorre no corpus de nosso estudo 
- uma vez que Lady Gaga quer, pode e deve jogar.

A música traz uma narrativa de paixão malevolente, de uma mulher que ama e quer um homem que ela sabe não amá-la, e que não é uma boa pessoa. Para a semiótica discursiva, as paixões, entendidas como "efeitos de sentido de qualificações modais que modificam o sujeito de estado" (BARROS, 2001, p. 47), afetam o sujeito da narrativa, pois são sentidas na alma. Nesse videoclipe, observam-se os seguintes estados do sujeito: a tristeza, pela ausência da pessoa amada, o medo de não conquistar o parceiro que deseja e a vingança por fazê-la sofrer. Todas essas paixões caracterizam-se como negativas e, por isso, desencadeiam ações malevolentes por parte de Sujeito Semiótico $1\left(S_{1}\right)$. Destacamos, também, que são as paixões de malevolência - ira, ódio, raiva - que impulsionam o $S_{1}$ para a ação em toda a narrativa visual, com destaque para a vingança no final do videoclipe, pois logo após ter conquistado seu objeto de valor, o homem amado, ela o mata.

O $\mathrm{S}_{1}$ manipula o sujeito semiótico $2\left(\mathrm{~S}_{2}\right)$, figurativizado pelo homem, por tentação, uma vez que a protagonista se oferece ao $\mathrm{S}_{2}$, como aquilo que ele não pode e não deve ficar sem. Ela se direciona ao $S_{2}$, exibindo-se para ele - canta e dança a história de uma mulher que quer e busca o amor ruim de um homem.

Evidenciamos que as figuras tematizam em todo o videoclipe uma isotopia relacionada à história e aos valores de um amor ruim e de tudo o que uma pessoa apaixonada é capaz de fazer para ter o seu amado, ou seja, seu Objeto de valor $\left(\mathrm{OV}_{1}\right)$. No fim da narrativa, destacamos que há uma ruptura da isotopia de submissão e de busca descontrolada pelo $\mathrm{OV}_{1}$ (amor-ruim), pois Lady Gaga, após alcançar o seu $\mathrm{OV}_{2}$ (o homem mau), por meio do casamento, rompe o contrato fiduciário de amor, respeito e fidelidade estabelecida com seu companheiro através do casamento, e sanciona-o negativamente, mesmo após ele ter cumprido sua parte no contrato, casando-se com ela. Ela vinga-se dele, logo após o casamento, matando-o na cama, logo após a cópula à semelhança da aranha Viúva Negra (Latrodectus).

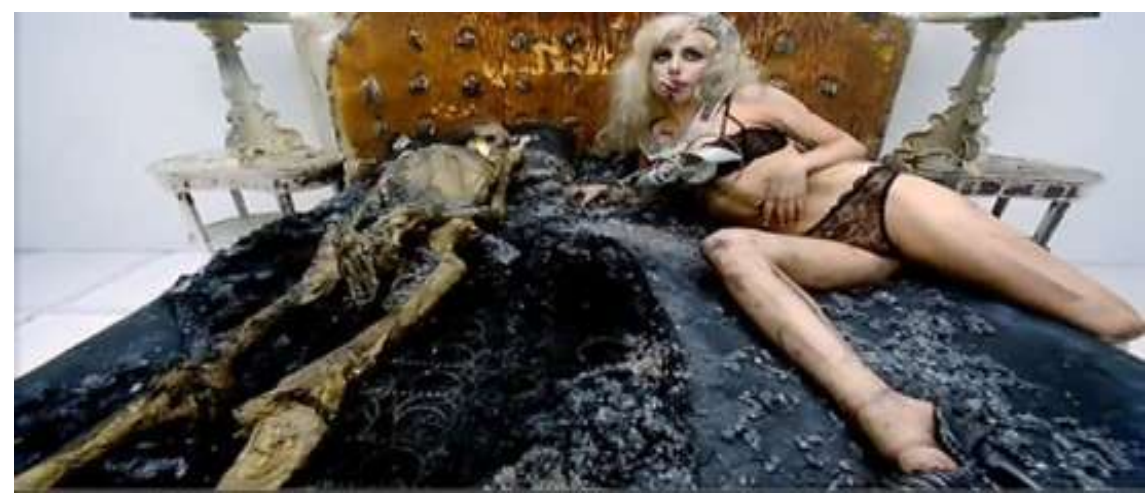

FIGURA 2 - Disponível em: https://www.youtube.com/watch?v=qrO4YZeyl0I Acesso em: 14 dez. 2016. 
$\mathrm{O}$ videoclipe todo concretiza visualmente a narrativa musical de um amor ruim: (i) $\mathrm{O} \mathrm{S}_{1}$ arrasta-se em direção ao seu objeto de valor 2 (o homem); (ii) a máscara de ferro na parte inferior do rosto do homem, para explicitar sua frieza e insensibilidade em relação ao sentimento feminino, ou seja, ele se apresenta como um homem de ferro, uma máquina que não tem coração; e (iii) o rosto de Lady Gaga, que demonstra indiferença e, até mesmo, prazer e satisfação, ao conseguir se vingar do parceiro. Temos, assim, no decorrer de toda a narrativa visual, uma história de amor, conquista e vingança que se estabelece por uma contradição entre o verbal e o visual, pois no plano verbal, Lady Gaga pede ao seu amado a sua vingança, ou seja, a vingança dele, e não sugere que será ela a se vingar.

\title{
3.2. Nível discursivo
}

De acordo com Barros (2002, p. 82),

\begin{abstract}
a teoria semiótica examina a enunciação enquanto instância pressuposta pelo discurso, em que deixa marcas ou pistas que permitem recuperá-la. Chega-se ao sujeito pelo caminho do discurso, reconstrói-se a enunciação por meio da análise interna do texto: certos procedimentos do texto marcam, nos diferentes patamares do percurso gerativo, a relação entre o discurso e a enunciação pressuposta. Podem-se citar, entre outros, a determinação axiológica, no nível das estruturas fundamentais, o conflito ideológico instalado na narrativa entre os destinadores do sujeito, os valores que o sujeito assume e suas paixões. Mas é sobretudo no nível das estruturas discursivas que a enunciação mais se revela, nas projeções da sintaxe do discurso, nos procedimentos de argumentação e na escolha dos temas e figuras, sustentadas nas formações ideológicas.
\end{abstract}

Dessa maneira, conforme Barros (2002, p.66) explica, é no nível discursivo que se estabelecem as relações entre enunciação e enunciado e entre enunciador e enunciatário, bem como tematização e figurativização dos valores narrativos.

Ao colocarmos essas relações nas cenas selecionadas para este estudo, verificamos que, em oposição à narrativa verbal contrapõe-se a narrativa visual, a qual mostra a figura de uma mulher nascendo, que busca e se prepara como uma boneca para conquistar um homem, um homem mau, com uma figura que se assemelha a uma caveira, e que traz para a vida dela um sentimento ruim, pois ele bebe e a olha com desdém. Dentre as imagens apresentadas, as que mais se destacam no videoclipe são as dos olhos, por diversas vezes retomados, reiterados por outra figura, a dos óculos.

Esse recurso figurativo dos olhos e dos óculos que aparece no nível discursivo com o tema Amor ruim, possibilita-nos uma leitura de que ela - Lady Gaga - olha para o objeto amado e o quer, mesmo que alguma coisa a impeça. Ela tira os óculos para manter seu foco e seus olhos no objeto de valor, pois, mesmo sabendo que ele é um amor ruim, ela o quer, e só tem olhos para ele. Todos esses efeitos de sentido são alcançados por meio das figuras, como, o nascimento da 
boneca, a caveira do homem, as garrafas de bebida, olhos, óculos, dentre outras, escolhidas e utilizadas para concretizar o tema de Bad Romance.

O sujeito semiótico 1 é posto em primeiro plano, cantando e olhando para o seu objeto de valor. Podemos observar, pela composição estrutural das cenas, que o sujeito semiótico 2 olha diretamente para o $S_{1}$ que, ora se deixa ser olhado, ora esconde o rosto, criando, dessa maneira, um efeito de sentido que alterna subjetividade (aproximação) e objetividade (distanciamento). Isso traz um efeito de realidade, como se o vídeo fosse uma cópia do real (BARROS, 2002). Esses efeitos de sentido são reiterados pelo texto oral.

Destacamos que a espacialidade é pouco explorada, pois todas as cenas se realizam dentro de um ambiente fechado, como se os sujeito semiótico 1 estivesse preso, não somente por um sentimento ruim, mas também em um local que não lhe permitisse enxergar nada além do seu ser amado $\left(S_{2}\right)$. O tempo aparece alternado entre um presente e um passado (marcado pela lembrança/imagens que vêm e vão).

No videoclipe temos o visual e a sensação do tátil juntos, pois o leitor pode ver e é como se ele pudesse sentir o calor do fogo incendiando e queimando o homem, no momento em que o $\mathrm{S}_{1}$ tira a roupa e se mostra vestindo uma lingerie branca, extremamente sensual, abrindo os braços e colocando as mãos e os dedos em uma posição de ataque.

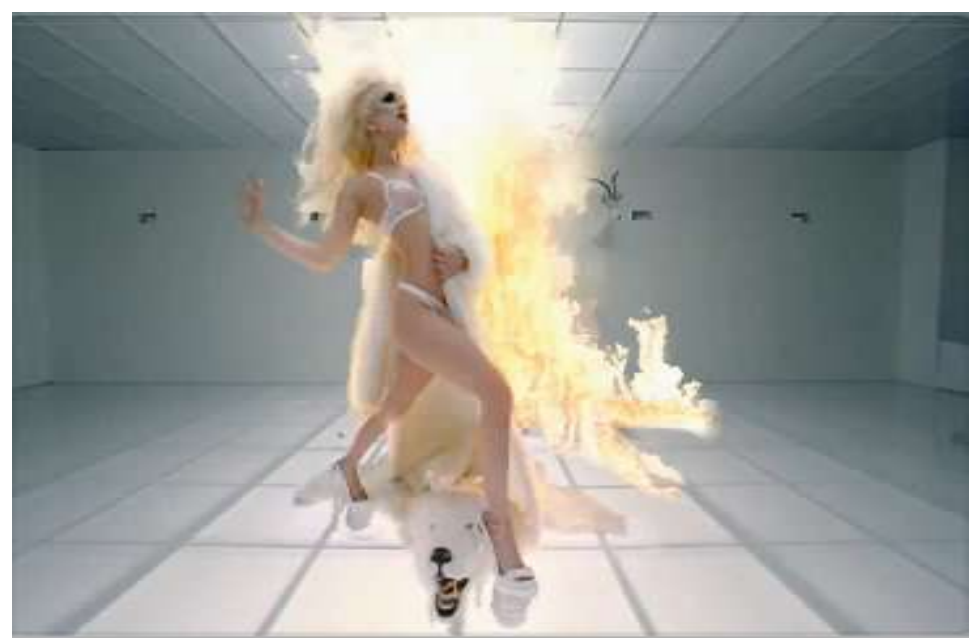

FIGURA 3 - Disponível em: https://www.youtube.com/watch?v=qrO4YZeyl0I Acesso em: 14 dez. 2016.

No fim do videoclipe, o leitor pode sentir o cheiro de queimado e ouvir o som do corpo do homem incendiando, além de ouvir, no final da apresentação, um barulho que encerra o videoclipe, com a imagem do fogo saindo dos seios de Lady Gaga e se dirigindo ao coração do homem que ela acabou de amar/matar. 


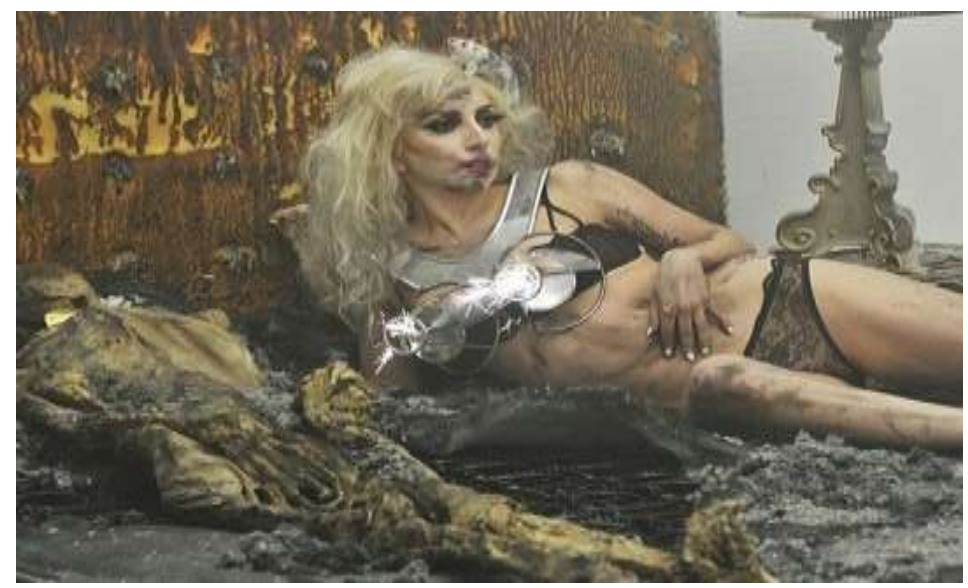

FIGURA 4 - Disponível em: https://www.youtube.com/watch?v=qrO4YZeyl0I Acesso em: 14 dez. 2016.

Assim, como nos explica Discini (2009), temos uma isotopia que se manifesta por complementaridade por meio de uma estratégia polêmica, na qual verbal e visual se negam mutuamente. Dessa forma, destacamos que esse videoclipe apresenta um tipo de estratégia contratual em que verbal e visual se contradizem para estabelecer uma isotopia temática e figurativa de controvérsia.

\subsection{Nível fundamental}

Barros (2002, p. 74) explica que "No nível das estruturas fundamentais, ponto de partida da geração do discurso, determina-se o mínimo de sentido a partir de que o discurso se constrói”. As estruturas fundamentais que verificamos em nosso corpus foi Natureza vs. Cultura. Natureza aparece revelada pela pulsão do indivíduo quando ele se instala no mundo com uma identidade e Cultura vem marcada pelas imposições e ordenamentos de uma comunidade social. Dessa forma, Lady Gaga é acoplada a oposição mínima de identidade vs autoridade sendo identidade o pólo do eu e autoridade o pólo do outro. Assim, quando afirmarmos o pólo da identidade ela se associa a natureza e disforiza a cultura e contrariando também o eixo da autoridade.

Podemos verificar, a partir de uma análise semiótica alicerçada nos principais conceitos do plano do conteúdo, níveis narrativo, discursivo e fundamental, que nos permitiram evidenciar a potencialidade dessa teoria da significação e sua utilização como um recurso teóricometodológico aplicado ao estudo de um videoclipe.

\section{As categorias cromática, topológica e eidética: um estudo das cenas do videoclipe}

Como foi salientado, Floch $(1985$, p.45) propõe um método de análise por meio do qual buscaremos compreender como se concretiza a homologação de categorias do plano do conteúdo com categorias do plano da expressão, a partir das categorias cromática, eidética e topológica. 
Destacamos, também, que as categorias propostas pelo teórico (1990, p. 24) interferem diretamente na criação e produção dos efeitos de sentido no texto em questão, o videoclipe, o que evidencia a relevância deste estudo.

\subsection{Cromatismo}

A respeito das cores, podemos observar o quanto o videoclipe explorou-as de forma a produzir os efeitos de sentido desejados pelo enunciador: seduzir o enunciatário, assim como o faz a mulher com seu amado. As cenas foram alternando tons fortes e tons pastéis, tornando possível criar efeitos de contraste e concretude, atribuindo uma maior plasticidade ao plano da expressão.

As cores seguiram a seguinte ordem: dourado, branco, preto, branco, casaco dourado com detalhes em preto, branco, preto, prata, branco, dourado, branco, preto, branco, vermelho, branco, vermelho, branco, encerrando com a cor preta, e foram utilizadas, sobretudo, nas vestimentas da actante (Lady Gaga) e do homem (o amor ruim [bad romance]).

Percebemos que tanto o branco quanto o preto são recorrentes. A cor branca é usada em diferentes roupas e em várias cenas. A cor branca é uma cor fria que simboliza a pureza e que, ao ser intercalada com cenas de vestimentas pretas, vai criando visualmente a passagem da pureza e da inocência para a maturidade, consciência do amor e dos problemas. Outra cor que sobressai é o vermelho, aparecendo nas lingeries quase ao final do videoclipe, momento em que se pode perceber a passagem do percurso da pureza, do desejo, para desencadear o percurso da ira e, principalmente, o da vingança. O vermelho é uma cor quente e simboliza a paixão, o desejo, o pecado, a raiva, o ódio.

Verifica-se, também, um contraste da cor preta, de outra lingerie, com a sua pele clara e com o louro de seus cabelos da Lady Gaga. Ressaltamos, ainda, o dourado, que também apareceu em várias cenas. O dourado é a cor que simboliza a riqueza, o poder, a força, enquanto que a cor prata, que também aparece, representa a frieza. Esse recurso de alternar cores fortes e claras enfatizam as cenas, criando uma continuidade que insere um efeito de sentido de pureza vs. impureza, permitindo ainda, no ato dessa alternância entre os tons contrastantes, introduzir a dicotomia bem vs. mal no nível fundamental da narrativa visual-musical de Bad Romance.

\subsection{Topologia}

As cenas selecionadas para este trabalho, optamos por considerar apenas duas passagens para uma melhor realização da análise. As cenas utilizadas para o estudo topológico são a primeira e a última, a fim de indicar onde principia e onde se encerra a narrativa. 


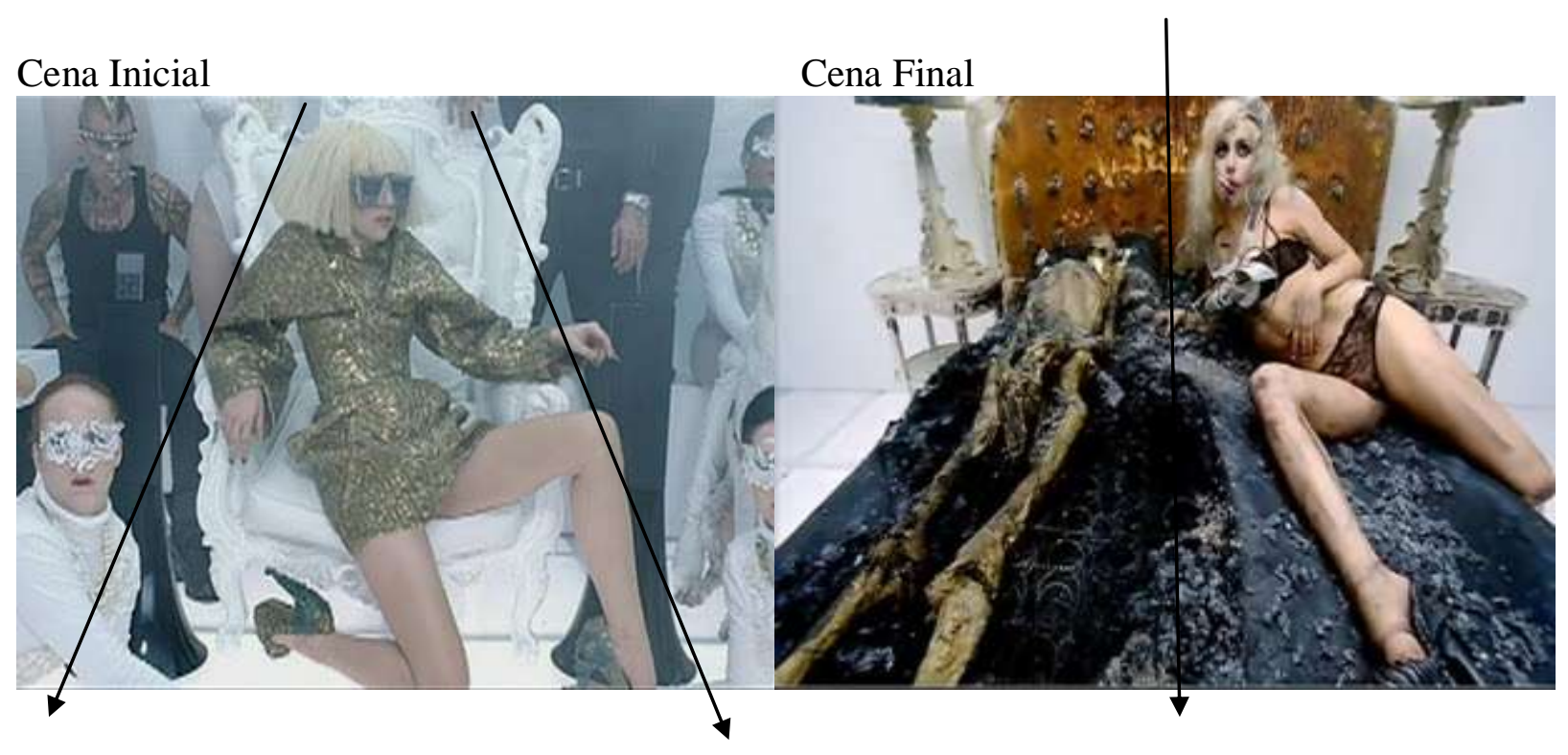

$\mathrm{Na}$ cena inicial, nosso olhar vai diretamente para o $\mathrm{S}_{1}$, que aparece ao centro. Nesse momento, o olhar do expectador pode ser atraído para a parte íntima da cantora, que tem as pernas entreabertas. Ela é o centro de tudo, é a figura para a qual todas as atenções se direcionam. A imagem da Lady Gaga vem ao centro propositalmente, para indicar que ela é o centro da narrativa, e que a música será narrada a partir dela. Isso se reitera na sucessão de cenas em que a centralidade do corpo da protagonista captura o olhar do internauta que assiste o videoclipe.

Já na cena final, podemos traçar uma linha imaginária dividindo-a ao meio, com dois corpos preenchendo o olhar do internauta. Do lado direito da cena, na horizontal, encontra-se Lady Gaga $\left(\mathrm{S}_{1}\right)$, com uma perna dobrada para fora da cama, um olhar perdido e um cigarro nos lábios, também podendo ser notada, na mão esquerda, a aliança de casamento. Do lado esquerdo da cena está a figura de um esqueleto carbonizado. Há uma linha imaginária que separa o casal na cama, pois embora ambos compartilhem o mesmo espaço, ele está morto e ela, viva. A cena que encerra a narrativa apresenta a Lady Gaga em uma posição mais alta que seu parceiro. Por meio desse videoclipe, verificamos apoiados em Tatit (2010), um ator se desfribila em vários papeis actanciais, assumindo em cada um deles uma ação.

\subsection{Eidético}

No nível eidético, notamos a oposição entre as formas dos elementos que compõem o plano da expressão. Verificamos, na constituição das cenas do videoclipe, que a maioria dos elementos são pontiagudos. Essas formas pontiagudas transmitem a ideia de sofrimento, atribuindo às cenas um sentido mais agressivo, indicado pelos saltos dos sapatos do $S_{1}$, pela ponta 
de seus chapéus (o preto e o branco), pelo seu cabelo, pelos chifres dos animais sobre a cama do casal, pelo sutiã de ponta, entre outros. O nível eidético enfatiza principalmente as marcas de agressividade e de dor explicitadas no videoclipe.

Ao analisarmos as categorias cromáticas, eidéticas e topológicas, verificamos que o sincretismo aglutina uma sucessão de efeitos sinestésicos no enunciatário - o que direciona o expectador a ver, ouvir e sentir a narrativa midiática do videoclipe.

\section{Considerações finais}

Por meio da análise do videoclipe Bad Romance, pudemos observar que a narrativa musical apresenta os traços da narrativa canônica desenvolvida por Greimas, ou seja, há um sujeito em busca de um objeto de valor - no caso de nosso corpus, a mulher que buscava conquistar o amor de um homem, mesmo sabendo que este era um amor ruim, apresentando uma narrativa de malevolência.

A partir de uma análise semiótica greimasiana, ancorada principalmente nas pesquisas de Floch $(1985,1987,1990$ e 2001) sobre o sincretismo, verificamos que no videoclipe existe uma contradição entre a narrativa verbal e a visual, o que Floch (1990) nomeou de estratégia de sincretização polêmica, uma vez que o conteúdo visual às vezes se opõe ao conteúdo verbal da narrativa, pois o sujeito da enunciação, ao escolher algumas linguagens, captura a atenção do enunciatário. Já no que se refere às categorias, destacamos: (i) os aspectos cromáticos se alternaram entre tons escuros (quentes) e claros (frios) para dar concretude às cenas, (ii) os aspectos topológicos direcionam o nosso olhar para a centralidade da cena, que vinha marcada com a presença da Lady Gaga, e (iii) os aspectos eidéticos evidenciam as formas pontiagudas que dominam e aparecem em todas as cenas para reforçar e reiterar a ideia de luta, dor e agressividade.

Ao analisarmos o nível narrativo, depreendemos que o videoclipe cria um efeito de sentido que parece estar em harmonia com a letra da música, na qual uma mulher parte para a ação, performance, em busca de seu $\mathrm{OV}_{1}$ (amor ruim), independentemente de saber que esse amor não é bom para ela, mas ao final do videoclipe, o que parece não é. O segredo é revelado: o $\mathrm{S}_{1}$ passa do estado inicial de amor para o estado do ódio e da vingança, matando seu parceiro logo após o casamento e a cópula. No nível discursivo, temos os temas do amor ruim e da dor causada em alguns relacionamentos marcados em todas as cenas, principalmente pelas figuras dos olhos e dos óculos, que concretizam o tema do amor ruim, evidenciando que, apesar de uma pessoa ver que um parceiro não é bom, prefere não enxergar o que se apresenta diante dos seus olhos. Depreendemos que todos esses efeitos de sentido foram alcançados pelas figuras que 
aparecem: boneca, caveira do homem, garrafas de bebida, olhos, óculos, dentre outras, materializando a temática da narrativa do Bad Romance.

Podemos também observar que os elementos sonoros, verbais e visuais que compuseram o videoclipe foram significativos para o seu receptor, principalmente com a presença da cantora Lady Gaga em um gran finale, rompendo a isotopia do amor e instaurando o primeiro estágio de não amor e depois o de ódio - o que ratifica a nossa análise. Assim sendo, constatamos, através deste estudo, que Bad Romance é uma narrativa sincrética que homologa os planos verbal, visual, e também o sensível.

\section{Referências:}

BARROS, Diana Luz Pessoa. Dialogismo, polifonia e enunciação. In: BARROS, Diana Luz Pessoa; FIORIN, José Luiz (Orgs.). Dialogismo, polifonia, intertextualidade. São Paulo, SP: Edusp, 2003.

. Teoria semiótica do texto. São Paulo: Ática, 2002.

A comunicação humana. In: Fiorin, José Luiz (Org.). Introdução à linguística: objetos teóricos. 5. ed. 2. reim. São Paulo: Contexto, 2001, p. 25-54.

BEIVIDAS, Waldir. Semióticas sincréticas (o cinema). Posições. (online). Disponível em <http://www.fflch.usp.br/dl/semiotica/downloads/down.html>. São Paulo: Edição Particular em Meio Eletrônico, 2006. ISBN 85-905252-1-X. Acesso em: 19 fev. 2017.

BERTRAND, Denis. Caminhos da semiótica literária. Bauru: Edusc, 2003. COELHO, Patrícia Margarida Farias. O advergame da Barbie e suas relações de manipulação sobre a jogadora-consumidora. In: $\mathbf{1}^{\mathbf{0}}$ Congresso Mundial de Comunicação Ibero- Americana - Confibercom 2011, 2011, São Paulo - USP. Confibercom 2011 - Sistemas de comunicação em tempos de diversidade cultural. v. 1, p. 1-16.

DISCINI, Norma. História em quadrinhos: um enunciado sincrético. In: OLIVEIRA, Ana Claudia de; TEIXEIRA, Lucia (Orgs.) Linguagens na comunicação: desenvolvimentos de semiótica sincrética. São Paulo: Estação das Letras e Cores, 2009.

FIORIN, José Luiz (Org.). Introdução à linguística: objetos teóricos. São Paulo: Contexto, 2009.

Polifonia textual e discursiva. In: BARROS, Diana Luz Pessoa; FIORIN, José Luiz (Orgs.). Dialogismo, polifonia, intertextualidade. São Paulo, SP: Edusp, 2003.

FLOCH, Jean Marie. Petites mythologies de l'oeil et l'esprit. Paris: Hàdes, 1985.

Sémiotique, marketing et communication: sous les signes, les stratégies. Paris: Puf. 1. édition. 1990.

. Semiótica plástica e linguagem publicitária (Trad. José Luiz Fiorin). Revista Significação no 6, p. 29-50, 1987.

Alguns conceitos fundamentais em semiótica geral. (Trad. Analice Dutra Pilar) Documentos de estudo do Centro de Pesquisas Sociossemióticas. São Paulo: Edições CPS. 2001.

GREIMAS, Algidas Julian; COURTÉS, Josep. Dicionário de semiótica. São Paulo: Editora Contexto, 2008. 
Sémiotique: dicionnaire raisoné de la théorie du language. Paris, Hachette, tomo 2, 1986.

OLIVEIRA, Ana Claudia de; TEIXEIRA, Lucia (Orgs). Linguagens na comunicação: desenvolvimentos da semiótica sincrética. São Paulo: Estação das Letras e Cores, 2009.

TATIT, Luiz. Semiótica à luz de Guimarães Rosa. São Paulo: Ateliê Editorial, 2010. 